\title{
T-box-mediated control of the anabolic proline biosynthetic genes of Bacillus subtilis
}

\author{
Correspondence \\ Erhard Bremer \\ bremer@staff.uni-marburg.de
}

Received 2 December 2010

Revised 7 January 2011

Accepted 11 January 2011

\section{Jeanette Brill, ${ }^{1}$ Tamara Hoffmann, ${ }^{1}$ Harald Putzer $^{2}$ and Erhard Bremer ${ }^{1}$}

\author{
${ }^{1}$ Philipps-University Marburg, Department of Biology, Laboratory for Microbiology, \\ Karl-von-Frisch-Str. 8, D-35032 Marburg, Germany \\ ${ }^{2}$ CNRS UPR 9073 Insitut de Biologie Physico-Chimique (affiliated with Université de Paris 7 - \\ Denis Diderot), 13 rue Pierre et Marie Curie, F-75005 Paris, France
}

Bacillus subtilis possesses interlinked routes for the synthesis of proline. The ProJ-ProA-ProH route is responsible for the production of proline as an osmoprotectant, and the ProB-ProA-Prol route provides proline for protein synthesis. We show here that the transcription of the anabolic proBA and prol genes is controlled in response to proline limitation via a T-box-mediated termination/antitermination regulatory mechanism, a tRNA-responsive riboswitch. Primer extension analysis revealed mRNA leader transcripts of 270 and $269 \mathrm{nt}$ for the proBA and prol genes, respectively, both of which are synthesized from SigA-type promoters. These leader transcripts are predicted to fold into two mutually exclusive secondary mRNA structures, forming either a terminator or an antiterminator configuration. Northern blot analysis allowed the detection of both the leader and the full-length proBA and pro/ transcripts. Assessment of the level of the proBA transcripts revealed that the amount of the full-length mRNA species strongly increased in proline-starved cultures. Genetic studies with a pro $B-t r e A$ operon fusion reporter strain demonstrated that proBA transcription is sensitively tied to proline availability and is derepressed as soon as cellular starvation for proline sets in. Both the proBA and the prol leader sequences contain a CCU proline-specific specifier codon prone to interact with the corresponding uncharged proline-specific tRNA. By replacing the CCU proline specifier codon in the proBA T-box leader with UUC, a codon recognized by a Phe-specific tRNA, we were able to synthetically re-engineer the proline-specific control of proBA transcription to a control that was responsive to starvation for phenylalanine.

\section{INTRODUCTION}

The amino acid proline serves several functions for the soildwelling Gram-positive bacterium Bacillus subtilis. Exogenously provided proline can be used as sole carbon and nitrogen source (Fisher \& Debarbouille, 2002). The role of proline as a nutrient is underscored by the finding that it is an excellent chemoattractant for B. subtilis (Ordal \& Gibson, 1977). Proline also serves as an important osmostress protectant (Bremer, 2002). For this task, proline can either be taken up by $B$. subtilis from the environment via the osmotically inducible OpuE transporter (Spiegelhalter \& Bremer, 1998; von Blohn et al., 1997) or be produced in very large quantities from the precursor glutamate (Belitsky et al., 2001; Whatmore et al., 1990). Proline belongs to a selected group of organic osmolytes, the compatible solutes, which are amassed by many micro-organisms to adapt to high-osmolarity growth conditions (Kempf \& Bremer, 1998). The cellular pools required for proline as a building block for protein synthesis and as an osmostress protectant are very different. Osmotically non-stressed $B$. subtilis cells have a proline pool of about $16 \mathrm{mM}$, and those subjected to a modest osmotic up-shock with $0.4 \mathrm{M} \mathrm{NaCl}$ amass proline to a concentration of about 0.5-0.7 M (Whatmore et al., 1990).

As in many other micro-organisms (Csonka \& Leisinger, 2007), proline biosynthesis in B. subtilis proceeds from glutamate and involves three enzymes: the $\gamma$-glutamyl kinase (ProB), the $\gamma$-glutamyl-phosphate reductase (ProA) and the $\Delta^{1}$-pyrroline-5-carboxylase reductase (ProI) (Fig. 1) (Belitsky et al., 2001). The activity of the ProB enzyme from $B$. subtilis is subjected to feedback control by proline (Chen et al., 2006), thereby tying proline production to proline consumption by the protein biosynthetic activities of the cell (Csonka \& Leisinger, 2007). Genetic studies have shown that in addition to the anabolic proline biosynthetic pathway formed by the ProB-ProA-ProI enzymes, a second route for proline biosynthesis is present in $B$. subtilis (Belitsky et al., 2001) that functions for the supply of the very large amounts of proline required for its use as an osmostress protectant (Bremer, 2002). This osmoadaptive proline biosynthetic route is formed by the ProJProA-ProH enzymes, and relies on isoenzymes for the first 


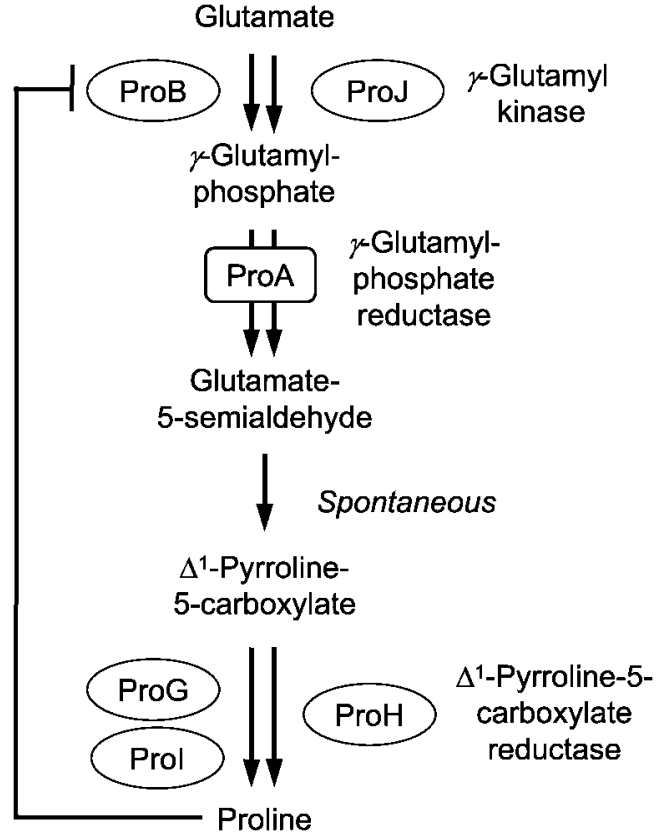

Fig. 1. Anabolic and osmoregulatory proline biosynthesis in $B$. subtilis. The proline biosynthetic enzymes and the intermediates of the enzymic conversion of glutamate into proline are indicated. Feedback inhibition of proline on the activity of the ProB enzymes is highlighted.

and last steps of the anabolic proline biosynthetic route (Fig. 1). Since no paralogous protein is present for the ProA enzyme, the anabolic and the osmodaptive proline biosynthetic routes in B. subtilis are interconnected by the $\gamma$-glutamyl-phosphate reductase (ProA) (J. Brill and E. Bremer, unpublished results) (Fig. 1). Expression of the proHJ operon is strongly upregulated in response to either suddenly imposed or sustained osmotic stress, whereas that of the proBA operon or that of the proA gene alone are not osmotically induced (Hahne et al., 2010; Steil et al., 2003). In addition to the ProI and ProH enzymes, the ProG protein also possesses $\Delta^{1}$-pyrroline-5-carboxylase reductase activity (Fig. 1), although the precise physiological function of the ProG protein is unresolved (Belitsky et al., 2001).

Bioinformatic mining of the $B$. subtilis genome sequence had indicated that the expression of the proBA operon and that of the proI $(y q j O)$ gene are genetically controlled through a T-box regulatory system (Chopin et al., 1998). T-box systems are widespread in Gram-positive bacteria, and are sensory and regulatory devices that prevent wasteful overproduction and overaccumulation of amino acids (Green et al., 2010; Gutiérrez-Preciado et al., 2009; Vitreschak et al., 2008; Wels et al., 2008; Winkler, 2007). Tbox systems are RNA-based regulatory switches (Henkin, 2008) that are used in many Gram-positive microorganisms to regulate the expression of aminoacyl-tRNA synthetase genes and of genes involved in amino acid biosynthesis and uptake (Green et al., 2010; GutiérrezPreciado et al., 2009; Winkler, 2007).

T-box-controlled genes typically possess very long $5^{\prime}$ untranslated mRNA segments that function as tRNAresponsive riboswitch elements and which can fold into mutually exclusive terminator or antiterminator secondary structures (Green et al., 2010; Gutiérrez-Preciado et al., 2009; Henkin, 2008; Vitreschak et al., 2008; Wels et al., 2008; Winkler, 2007). The amino acid specificity of a given T-box system is conferred through a single codon, the specifier (Grundy \& Henkin, 1993), which is present in the 5'untranslated region of each T-box-controlled gene (Foy et al., 2010; Green et al., 2010; Gutiérrez-Preciado et al., 2009; Henkin, 2008; Vitreschak et al., 2008; Wels et al., 2008). The decision between premature termination of transcription and transcription of the full-length gene is made through the combined interactions of the anti-codon of an uncharged cognate tRNA with the specifier codon and the highly conserved $5^{\prime}$-NCCA- $3^{\prime}$ sequence in the acceptor stem of the non-acylated tRNA with a conserved $5^{\prime}$-UGGN-3' sequence in the T-box. These interactions cannot occur when a tRNA is aminoacylated (Putzer et al., 2002). Interactions of the non-acylated tRNA with elements present in the mRNA leader sequence lead to a stabilization of the antiterminator configuration of the riboswitch and thus permit transcription of the full-length gene to proceed (Green et al., 2010; Gutiérrez-Preciado et al., 2009). T-box regulatory systems monitor the ratio between the charged and uncharged forms of a specific tRNA (Grundy et al., 2005; Yousef et al., 2005), and thereby allow an assessment of the cellular pool of a particular amino acid. Gene regulation via T-box-dependent regulatory switches prevents wasteful overproduction via synthesis or overaccumulation via transport of a particular amino acid (Green et al., 2010; Gutiérrez-Preciado et al., 2009; Henkin, 2008; Winkler, 2007).

Here we demonstrate that the transcription of the anabolic proBA and proI proline biosynthetic genes of $B$. subtilis is sensitively regulated via a T-box system in response to proline starvation. Although proline-responsive T-box systems are predicted to occur widely in Gram-positive bacteria (Gutiérrez-Preciado et al., 2009; Vitreschak et al., 2008; Wels et al., 2008), the data reported here on the regulation of the proBA and proI genes of $B$. subtilis provide, to the best of our knowledge, the first experimental proof for the functionality of a proline-responsive T-box system in any micro-organism.

\section{METHODS}

Bacterial strains. For routine cloning experiments we used the Escherichia coli strain DH5 $\alpha$ (Clontech). All B. subtilis mutant strains used in this study are derivatives of the wild-type strain JH642 (BGSC 1A96; a kind gift of J. Hoch, Scripps Research Institute, CA, USA) and are listed in Table 1.

Growth conditions. The B. subtilis strains were cultivated in Spizizen's minimal medium (SMM) with $0.5 \%(\mathrm{w} / \mathrm{v})$ glucose as the 
Table 1. B. subtilis strains used in this study

\begin{tabular}{|c|c|c|}
\hline JH642 & trpC2 pheA1 & BGSC $† 1 \mathrm{~A} 96$ \\
\hline FSB1 & $\Delta($ treA:: neo $) 1$ & Spiegelhalter \& Bremer (1998) \\
\hline JSB5 & amyE: :[Ф(proB'-treA $) 1$ 'ykkE cat $] \Delta($ treA : : neo $) 1$ & This study \\
\hline JSB8 & $\Delta($ proHJ: : tet $) 1$ & This study \\
\hline JSB9 & $\Delta($ proI: : spc $) 1$ & Belitsky et al. (2001) \\
\hline JSB13 & $\Delta($ proHJ: : tet $) 1 \Delta($ proI: : spc $) 1$ & This study \\
\hline JSB17 & $\operatorname{proA} \times \operatorname{pEPV} 1 \mathrm{~T}($ tet $)$ & This study \\
\hline JSB31 & amyE:: $[\Phi($ proB'-treA $) 1$ ' $y k k$ cat $](\Delta$ treA : : neo $) 1$ proA $\times$ pEPV1T $($ tet $)$ & This study \\
\hline JSB31-mut1 & amyE:: $\left[\Phi(\right.$ proB'-tre $A) 2^{\prime} y k k E$, cat $](\Delta t r e A::$ neo $) 1$ proA $\times$ pEPV1T $($ tet $)$ & This study \\
\hline JSB34 & proA $\times$ pEPV1T $($ tet $)(\Delta$ treA::neo $) 1$ & This study \\
\hline JSB41 & $\Delta($ proHJ:: tet $) 1 \Delta($ proI::spc $) 1 \Delta($ proG:: ble $) 1$ & This study \\
\hline
\end{tabular}

${ }^{*}$ All strains, except BB1951, are derivatives of JH642 and therefore also carry the trpC2 pheA1 mutations.

$\dagger$ Bacillus Genetic Stock Center.

carbon source and L-tryptophan $\left(20 \mathrm{mg} \mathrm{l}^{-1}\right)$ and L-phenylalanine $\left(18 \mathrm{mg}^{-1}\right)$ to satisfy the auxotrophic growth requirements of strain JH642 (trpC2 pheA1) and its derivatives (Table 1). A solution of trace elements was added to SMM (Harwood \& Archibald, 1990). All B. subtilis cultures were inoculated from exponentially growing precultures in pre-warmed minimal media to $\mathrm{OD}_{578} 0.1$ and the cultures were subsequently propagated at $37{ }^{\circ} \mathrm{C}$ in a shaking water bath set to 220 r.p.m. The B. subtilis cells were grown in either 20 or $75 \mathrm{ml}$ culture volumes in 100 or $500 \mathrm{ml}$ Erlenmeyer flasks, respectively. For amino acid limitation experiments, the B. subtilis cells were pregrown in SMM with an excess of the appropriate amino acid, and the cultures were washed twice with SMM without added amino acids and then used to inoculate the main culture in SMM containing either excess $(10 \mathrm{mM})$ or limiting amounts $(0.2,0.4,0.8$ or $1.2 \mathrm{mM})$ of proline. For experiments that involved starvation for phenylalanine, cultures were grown either with excess $(0.1 \mathrm{mM})$ or limiting amounts $(0.016 \mathrm{mM})$ of this amino acid. The antibiotics chloramphenicol $\left(5 \mu \mathrm{g} \mathrm{ml}^{-1}\right)$, zeocin $\left(35 \mu \mathrm{g} \mathrm{ml}^{-1}\right)$, tetracycline $(15 \mu \mathrm{g}$ $\left.\mathrm{ml}^{-1}\right)$, erythromycin $\left(1 \mu \mathrm{g} \mathrm{ml}^{-1}\right)$ and spectinomycin $\left(100 \mu \mathrm{g} \mathrm{ml}^{-1}\right)$ were used for the selection of gene disruption mutations in B. subtilis (Table 1) after DNA transformation with chromosomal DNA. Ampicillin was used at a final concentration of $100 \mu \mathrm{g} \mathrm{ml}^{-1}$ for $E$. coli cultures carrying plasmids.

Chemicals. Ampicillin, chloramphenicol, tetracycline, erythromycin and spectinomycin were purchased from Sigma-Aldrich. Zeocin was purchased from Invitrogen. The chromogenic substrate [paranitrophenyl- $\alpha$-D-glucopyranoside (PNPG)] for TreA enzyme assays was purchased from Sigma-Aldrich.

Construction of plasmids. Plasmid pBKB26 carries a $2.75 \mathrm{~kb}$ 'ykkE-proB-proA' DNA fragment cloned into the BamHI and EcoRI sites of the low-copy-number vector pHSG575 (B. Kempf and E. Bremer, unpublished data). A $2.75 \mathrm{~kb}$ Sall-EcoRI DNA fragment ('ykkE-proB-proA') from pBKB26 was cloned into the Sall- and EcoRI-restricted pBluescriptSK ${ }^{-}$vector (Stratagene), thereby yielding plasmid pJS3. For the construction of the proBA gene disruption mutation, a HindIII and BclI fragment (224 bp) was deleted from plasmid pJS3 and replaced with a chloramphenicol-resistance cassette derived from plasmid pRMK59 (Kappes et al., 1999), resulting in plasmid pJS8. A proBA-treA reporter gene fusion was constructed as follows. The $1.05 \mathrm{~kb}$ MunI-Sau3A DNA fragment derived from pBKB26, carrying the proB regulatory region and part of the proB coding sequence (B. Kempf and E. Bremer, unpublished data), was inserted into the vector pBluescriptSK ${ }^{-}$that had been cleaved with EcoRI and BamHI; this construction yielded plasmid pJS2. The $1.02 \mathrm{~kb}$ EcoRV-Sau3AI proB fragment derived from pJS2 was then inserted into the SmaI and BamHI sites present in the polylinker of the low-copy-number treA reporter plasmid pJMB1 (M. Jebbar and E. Bremer, unpublished results), thereby yielding a proB-treA operon fusion (present on plasmid pJS5) with treA as the reporter gene (Gotsche \& Dahl, 1995; Schöck et al., 1996). To construct a proHJ:: tet gene disruption mutation, we first amplified the ' $r t p-$ proH-proJ-glt $C^{\prime}$ region from the B. subtilis chromosome of strain JH642 via PCR, cleaved it with $S c a \mathrm{I}$ and MunI, and then inserted the resulting restriction fragment $(2578 \mathrm{bp})$ into plasmid pBluescriptSK ${ }^{-}$ that had been cleaved with EcoRI and EcoRV; this yielded plasmid pJS13. A $1.9 \mathrm{~kb}$ PstI-XbaI restriction fragment, carrying a tetracycline-resistance cassette, was isolated from plasmid pBEST307 (Itaya, 1992) and ligated into the plasmid backbone of pJS13 cleaved with NsiI and AvrII. In the resulting plasmid, pJS19, an internal DNA segment of the proHJ operon $(1.089 \mathrm{~kb})$ was replaced by the tet resistance cassette.

Construction of B. subtilis strains. Strain JSB $11[\Delta($ proBA : : cat $) 1]$ was isolated after transformation of strain JH642 with DNA of plasmid pJS8 (linearized with the restriction enzymes BamHI and EcoRI) and subsequent selection for chloramphenicol-resistant transformants. Strain JSB17 [proA $\times$ pEPV1T $($ tet $)$ ] was isolated after transformation of strain JH642 with the circular plasmid pEPV1T (Ogura et al., 1994) and selection for tetracycline-resistant colonies; in this strain, plasmid pEPV1T is inserted into the proA gene via a Campbell-type single-crossover integration event, thereby disrupting the integrity of proA. The proA mutation present in strain JSB17 was introduced into strain FSB1 [(treA::neo) 1] (Spiegelhalter \& Bremer, 1998) by DNA transformation with chromosomal DNA from strain JSB17 and subsequent selection for tetracycline-resistant colonies. This yielded strain JSB34 [ $\Delta($ treA : : neo $)($ proA $\times$ pEPV1T $(t e t)]$. The proB-treA operon fusion present in plasmid pJS5 was introduced into various $B$. subtilis strains by transforming linearized plasmid DNA (pJS5 cleaved with PstI and XhoI) and selecting for chloramphenicolresistant transformants. In this way, the proB-treA gene fusion was 
recombined via its flanking $5^{\prime}$ and $3^{\prime} a m y E$ DNA sequences into the $B$. subtilis chromosome, yielding a genetically stable, single-copy amyE: :proB-treA-cat:: amyE insertion. Strain JSB8 $[\Delta($ proHJ::tet $) 1]$ was isolated by transforming linear DNA of plasmid pJS19 (cleaved with BamHI) into strain $\mathrm{JH} 642$ and subsequently selecting for tetracycline-resistant transformants. The $[\Delta$ (proHJ:: tet $) 1]$ mutation was then introduced into strain JSB9 (Belitsky et al., 2001) by transforming it with chromosomal DNA of strain JSB8 and selecting for tetracycline-resistant colonies. This yielded strain JSB13 [ $\Delta$ (proI::spc) $1 \Delta$ (proHJ::tet) 1] (Table 1). For the construction of a strain defective in all three genes encoding the enzyme for the last step in proline biosynthesis (Fig. 1), chromosomal DNA of the B. subtilis strain BB1951 (Belitsky et al., 2001) carrying the $\Delta$ (proG:: ble) allele was transformed into strain JSB13, and zeocin-resistant transformants were selected; this yielded strain JSB41 $[\Delta($ proI::spc $) 1$ $\Delta($ proHJ: : tetl $) \Delta($ proG::ble $) 1]$.

TreA enzyme assays. The expression of chromosomal proB-treA fusions was monitored by assaying the TreA [phospho- $\alpha-(1,1)$ glucosidase] enzyme activity using the chromogenic substrate PNPG (Gotsche \& Dahl, 1995). TreA enzyme activity is expressed as U (mg protein $)^{-1}$ according to the definition used for the quantification of $\beta$-galactosidase (Miller, 1992). Protein concentrations of the samples were estimated from the optical density of the cell culture. In each of the proB-treA fusion strains, the natural copy of treA in the B. subtilis chromosome is disrupted (Table 1), so that the measured TreA enzyme activity in the reporter strain reflects solely that encoded by the reporter fusion. Strain TRB0 (Table 1) carries a promoterless treA gene derived from plasmid pJMB1 inserted into the chromosomal amyE locus, and this strain was always used as a control for the proBtreA fusion experiments. Background TreA activity exhibited by strain TRB0 was subtracted from the TreA activities exhibited by proB-treA fusion strains.

Methods used with nucleic acids. Routine manipulations of plasmid DNA, PCR, the construction of recombinant plasmids and the isolation of chromosomal DNA from B. subtilis were carried out according to standard procedures (Sambrook et al., 1989). The nucleotide sequences of cloned PCR fragments and of mutations generated via site-directed mutagenesis were verified by the chaintermination method using the Thermo Sequenase fluorescent labelled primer cycle sequencing kit (Amersham Pharmacia Biotech). The DNA-sequencing reactions were primed with synthetic oligonucleotides labelled at their $5^{\prime}$ end with the infrared dye IRD-800 (Eurofins), and the products were analysed on a LI-COR DNA sequencer (model 4000) (Eurofins).

RNA isolation and Northern blot analysis. Total RNA from $B$. subtilis was isolated by phenol extraction as described previously (Holtmann \& Bremer, 2004). Cells were grown in SMM under the indicated conditions and samples were harvested either in midexponential phase $\left(\mathrm{OD}_{578} 0.5-0.8\right)$ or at specified points during the growth cycle. RNA was routinely isolated from $20 \mathrm{ml}$ cultures. The total amount of RNA isolated was determined spectrophotometrically $\left(A_{260}\right)$; an $A_{260}$ of 1 corresponds to approximately $40 \mu \mathrm{g} \mathrm{RNA} \mathrm{ml} \mathrm{m}^{-1}$ (Sambrook et al., 1989). Samples $(15 \mu \mathrm{g})$ of total RNA were electrophoretically separated on a $1.4 \%$ agarose gel, transferred to a Schleicher \& Schuell NY13N membrane, and hybridized with a DIGlabelled single-strand DNA probe specific for either proB or proI, respectively, using conditions specified by the manufacturer of the Northern hybridization and digoxigenin detection kit (Roche Diagnostics). The hybridization products were visualized with the chemiluminescent reagent ECF-Vistra $\left(12 \mu \mathrm{l}\right.$ per $\mathrm{cm}^{2}$ of blotting membrane) (Amersham Pharmacia Biotech) and a Storm 860 Phosphorimager (Amersham Pharmacia Biotech). The $1056 \mathrm{nt}$ DNA probe specific for proB (probe 1, Fig. 5b) was prepared from plasmid pJS2 using the Strip-EZ RNA kit (Ambion) in combination with DIG-UTP (Roche Diagnostics). The DIG-labelled single-strand 86 nt DNA probe specific for the proB leader (probe 2, Fig. 5b) was prepared from a PCR fragment, generated with oligonucleotides carrying an artificial T7-promoter sequence at the $3^{\prime}$ end. This probe begins $103 \mathrm{nt}$ downstream of the proBA transcription initiation site and does not cover the specifier codon or the intrinsic terminator sequence; its $3^{\prime}$ end is localized at the -UGGU- sequence within the T-box.

Primer extension analysis. To map the $5^{\prime}$ ends of the proBA and proI transcripts, we used primer extension analysis. Total RNA from a $75 \mathrm{ml}$ culture of the B. subtilis wild-type strain JH642 that had been grown in SMM to mid-exponential phase $\left(\mathrm{OD}_{578} 0.8\right)$ was isolated as described above. Reverse-transcriptase assays for the proBA and proI mRNAs were carried out with $15 \mu \mathrm{g}$ total RNA and about 2 pmol of either a ${ }^{32} \mathrm{P}-5^{\prime}$-end-labelled proBA-specific oligonucleotide $\left(5^{\prime}\right.$ TCTCTGTCACAGAAAGGTCTGC-3') or an IRD-800-fluorescenceend-labelled proI-specific oligonucleotide (5'-TTTTCCTAACCGCGACTTGAGGGC-3'). Reverse-transcriptase reactions were carried out with a Primer Extension System-AMV Reverse Transcriptase kit purchased from Promega. The size of the proBA reverse transcript was analysed on a denaturing $5 \%$ polyacrylamide DNA sequencing gel. The same DNA primer employed for the proBA reverse transcription reaction was used in a DNA sequencing reaction with plasmid pJS2 to determine the exact position of the $5^{\prime}$ ends of the proB mRNA. The size of the proI reverse transcript was analysed on a LI-COR DNA sequencer (model 4000) (Eurofins). The DNA primer employed for the proI reverse transcription reaction was used with plasmid pJS18 (Belitsky et al., 2001) to determine the exact position of the $5^{\prime}$ end of the proI mRNA.

Site-directed mutagenesis. Site-directed mutagenesis was used to change the proline-specific specifier codon (CCT) present in the untranslated leader region of the proBA operon (Fig. 2a) to a phenylalanine-specific TTC codon. Site-directed mutagenesis was performed on the proB-treA wild-type fusion present in plasmid pJS5 using the QuikChange Site-Directed Mutagenesis kit (Agilent Technologies) and a custom-synthesized oligonucleotide (Eurofins). The presence of the desired change in the proBA leader region was verified by DNA sequence analysis. The resulting mutant proB-treA reporter fusion plasmid pJS5-mut1 was linearized by digestion with $X h o \mathrm{I}$ and PstI, and the fusion was recombined as a single copy into the amyE site of the B. subtilis $\Delta($ treA::neo) strain FSB1 (Table 1) by selecting for chloramphenicol-resistant colonies. The resulting strain was then used for further genetic manipulations to introduce a proA mutation into this background (Table 1).

Computer analysis of DNA, RNA and protein sequences. Alignments of the amino acid and DNA sequences were performed with the Vector NTI software package (Invitrogen). The proBA and proI leader mRNA structures were predicted using the Mfold algorithm (Zuker, 2003). The mRNA secondary structures suggested by the program (http://mfold.rna.albany.edu/) were then further manually adjusted based on phylogenetic considerations.

\section{RESULTS}

\section{Mapping of the proBA and prol transcription initiation sites}

To map the transcription initiation sites of the proBA and proI loci from $B$. subtilis, we carried out a primer extension analysis. Total RNA was isolated from exponentially growing cultures of the wild-type strain JH642 and 
(a) $\operatorname{proBA}$
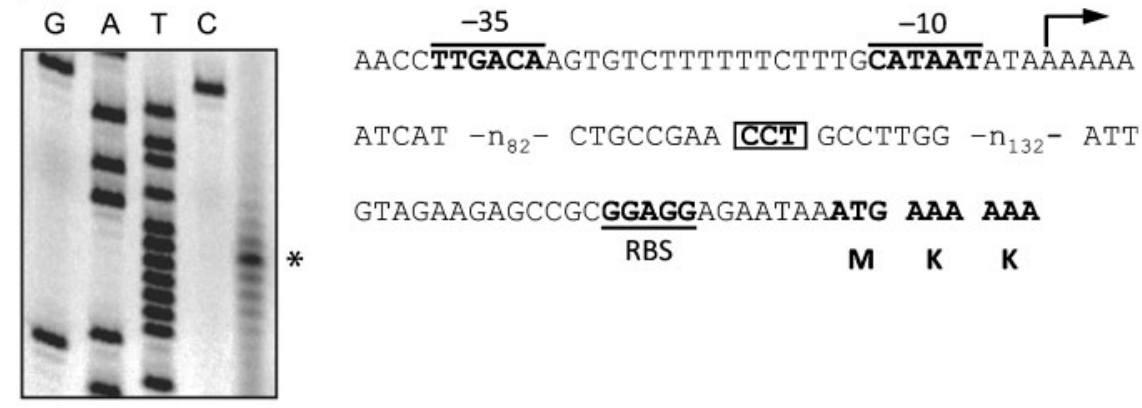

ATCAT $-\mathrm{n}_{82}-$ CTGCCGAA CCT GCCTTGG $-\mathrm{n}_{132}-$ ATT

GTAGAAGAGCCGCGGAGGAGAATAAATG AAA AAA

RBS M K K

(b) prol

G A T C

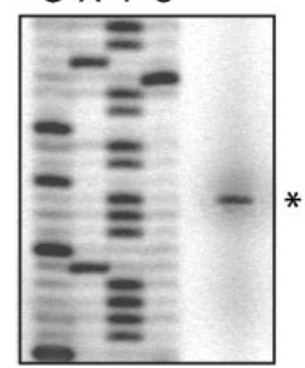

$\frac{-35}{\text { ATTGACATTAGCTTGTCCGCCATTG }} \frac{-10}{\overrightarrow{C A T A A T}} \underset{\overrightarrow{T A A C A A C A A A}}{\overrightarrow{1}}$

CTAAA $-\mathrm{n}_{96}-$ TTGTAGAA CCT GCCCTCA $-\mathrm{n}_{121}-$ GTT

GTTCTAATAGAAGgAGgATATCAATG AAA AAG

RBS
M K K

Fig. 2. Mapping of the proBA (a) and prol (b) transcription initiation sites by primer extension analysis. The $5^{\prime}$ ends of the proBA and prol transcripts were mapped using mRNA isolated from the proline-prototrophic strain JH642; the asterisk indicates the cDNA fragment generated via the primer extension procedure. The determined $5^{\prime}$ ends of the mRNAs (marked by arrows) are projected onto the DNA sequences of the proBA and prol regulatory regions. Putative SigA-dependent promoter sequences ( -10 and -35 regions) are indicated. The proline-specific CCT specifier codons of the proBA and prol transcripts are boxed. The putative ribosome-binding sites (RBS) are underlined, and the translational initiation codons of the proB and prol genes are indicated.

hybridized with labelled single-stranded oligonucleotide DNA probes specific for either the proBA or proI mRNA transcripts. A single primer extension reaction product was found for both the proBA and the proI transcripts (Fig. 2a, b). The transcription initiation sites for the proBA operon and the proI gene are positioned 270 and 269 bp upstream of the predicted ATG start codons of proB and proI, respectively (Fig. 2a, b). Inspection of the DNA sequence upstream of the mapped $5^{\prime}$ ends of both transcripts revealed appropriately spaced -10 and -35 elements for both the proBA and the proI gene that closely resemble those of typical SigA-type housekeeping promoters of $B$. subtilis (Fig. 2a, b) (Helmann, 1995).

\section{Predicted secondary structures of the T-box leaders in the proBA and prol mRNA sequences}

Earlier bioinformatic inspection of the B. subtilis genome sequence had suggested the presence of elements characteristic of T-box regulatory systems in the $5^{\prime}$ mRNA regions of both the proBA and the proI gene (Chopin et al., 1998; Gutiérrez-Preciado et al., 2009; Vitreschak et al., 2008; Wels et al., 2008; Winkler, 2007). We analysed the proBA and proI leader sequences using Mfold (Zuker, 2003) and some manual adjustments to draw the secondary structures of the leader mRNAs (Fig. 3a, b). They revealed the presence of all major elements characteristically required for genetic control via tRNA-mediated antitermination. These include a factor-independent transcription terminator and the T-box sequence. The T-box sequence is part of a mutually exclusive terminator and antitermination mRNA structure present in both of the predicted mRNA leader elements of proBA and proI (Fig. 3a, b). Furthermore, the predicted mRNA secondary structures for both loci contain a CCU triplet (a proline-specific codon) in a bulged segment of the folded proBA and proI specifier domain, a region that typically contains the specifier codon for a given T-box system (Green et al., 2010; Gutiérrez-Preciado et al., 2009; Vitreschak et al., 2008). The mRNA secondary structures predicted for the proBA and proI leader regions closely resemble one another (Fig. 3a, b), and this is reflected in the considerable nucleotide sequence identity (59\%) of the proBA and proI leader sequences. Neither the proG gene nor the proHJ operon is predicted to possess a T-box element.

The presented in silico data suggest that a T-box regulatory circuit controls the expression of the proBA and proI genes. 
(a) $\operatorname{proBA}$

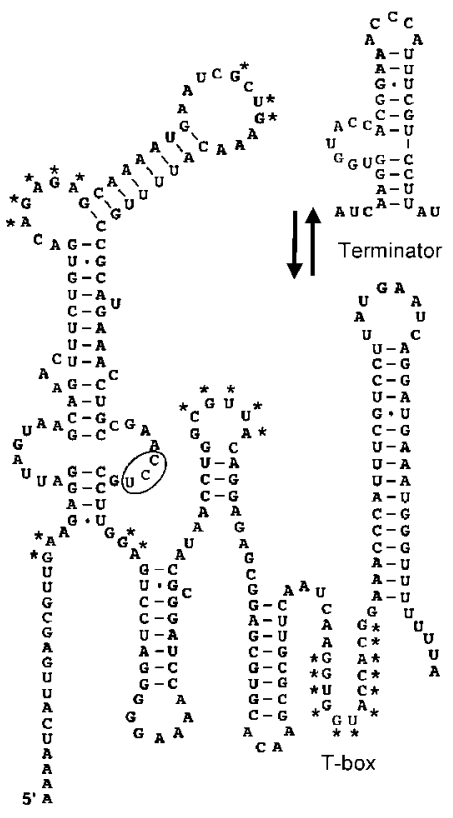

(b) prol

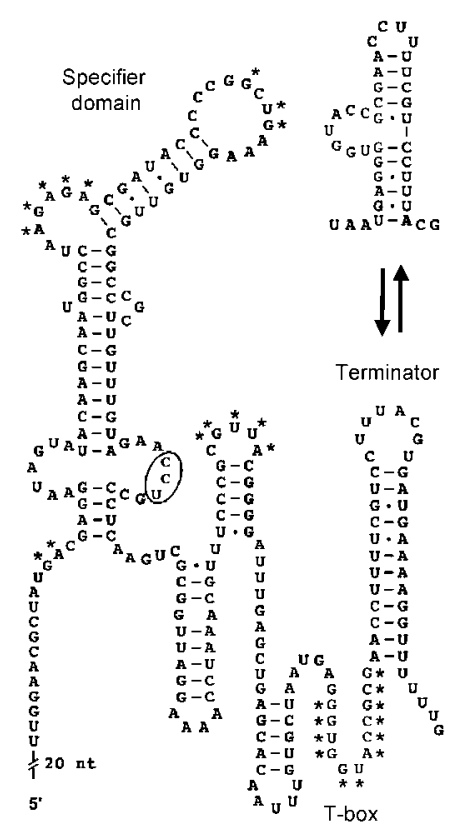

Fig. 3. Predicted secondary structures of the proBA (a) and prol (b) leader transcripts. The secondary structure of the $5^{\prime}$ regions of the proBA and prol transcripts were predicted with Mfold and edited manually for their termination and antitermination configurations. The suggested proline-specific specifier codons for the proBA and prol genes and the T-box sequences are indicated.
Consequently, short leader proBA and proI transcripts should be constitutively synthesized in $B$. subtilis cells that are not starved for proline. These transcripts should comprise the T-box leader mRNA element up to the intrinsic terminator sequence ending with a run of $U$ nucleotides (Fig. 3a, b); both the prematurely terminated proBA and proI leader transcripts have a calculated length of $241 \mathrm{nt}$. To test for the presence of these short mRNA species, we carried out Northern blot analysis of total RNA isolated from B. subtilis cells of strain JH642 that were not starved for proline. As documented in Fig. 4, the predicted proBA and proI mRNA leader sequences were readily detected; their estimated lengths of about $200 \mathrm{nt}$ are in good agreement with those predicted from the position of the intrinsic terminators in the proBA and proI mRNA leader sequences (Fig. 3a, b). In these Northern blot experiments, we also detected an approximately $2700 \mathrm{nt}$ proBA and an approximately $1200 \mathrm{nt}$ proI mRNA species. The sizes of these mRNA species correspond to those calculated for full-length mRNA transcripts of the proBA operon (about $2680 \mathrm{nt}$ ) and of the proI gene (about $1150 \mathrm{nt}$ ) initiating from the mapped promoters (Fig. 2a, b) and extending to putative factor-independent transcription terminators positioned immediately downstream of the proA and proI coding regions.

\section{Northern blot analysis of the proBA transcripts during proline starvation}

For further analysis of the T-box-mediated transcriptional control of the anabolic proline biosynthetic genes in $B$. subtilis, we focused on the proBA operon. In T-boxcontrolled genes, read-through transcription past the intrinsic terminator sequence present in the mRNA leader sequence will increase in cells that are starved for the particular amino acid determined by the specifier codon (Green et al., 2010; Gutiérrez-Preciado et al., 2009; Henkin, 2008; Winkler, 2007). Hence, the level of the full-length transcript will increase and thereby provide the starved cell with proteins that will offset starvation for a particular amino acid. To visualize both the proBA mRNA leader and the full-length transcripts in cells starved of proline, we performed a Northern blot analysis of total RNA isolated from the B. subtilis mutant strain JSB41. This strain is a proline auxotroph in which the genes encoding three paralogous $\Delta^{1}$-pyrroline-5-carboxylate-reductases (ProG, ProH and ProI) (Fig. 1) are simultaneously disrupted (Table 1) (Belitsky et al., 2001). For this experiment, we grew strain JSB41 in SMM in the presence of either excess $(10 \mathrm{mM})$ or limiting amounts $(0.6 \mathrm{mM})$ of proline, and total RNA was isolated from these two cultures as soon as the growth of the proline-limited culture began to slow down (Fig. 5a). In cells that were not starved for proline, both the $200 \mathrm{nt}$ leader transcript and the $2700 \mathrm{nt}$ fulllength transcript were detected with a single-stranded DNA probe (probe 1) that covered both the proBA leader region and $575 \mathrm{bp}$ of the proB coding region (Fig. 5b). These two proBA transcripts were also present in proline-starved cells of strain JSB41, but the amount of the full-length proBA transcript was strongly increased in comparison with cells grown with excess proline (Fig. $5 \mathrm{c}$ ). Hence, in agreement with the anticipated T-box-mediated control of proBA expression in B. subtilis, synthesis of the full-length proBA transcript is substantially enhanced in proline-starved cells.

In addition to the $200 \mathrm{nt}$ proBA mRNA leader and the fulllength mRNA species (2700 nt), we also detected an additional mRNA species $(\sim 2500 \mathrm{nt})$, whose amount was 


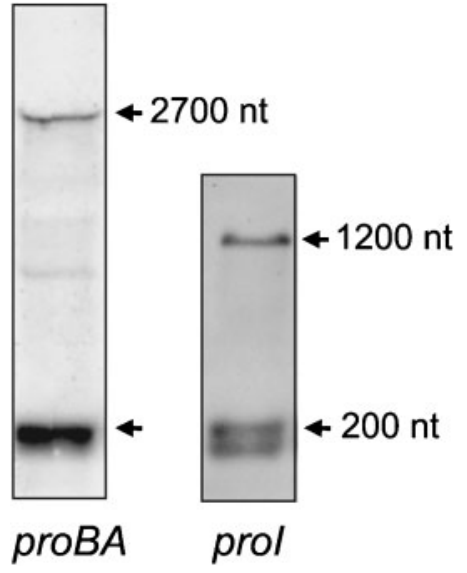

Fig. 4. Northern blot analysis of the proBA and prol transcripts in cells that are not starved for proline. Cells of the prolineprototrophic strain $\mathrm{JH} 642$ were grown to the mid-exponential growth phase, and total RNA was prepared and separated according to size under denaturing conditions on a $1.4 \%$ agarose gel; then the proBA- and prol-specific transcripts were detected by hybridization with DIG-labelled single-stranded DNA probes. Arrows mark the proBA and prol leader and full-length transcripts.

also increased in proline-starved cells of strain JSB41 (Fig. 5c). This mRNA species represents in all likelihood a processed product of the full-length $2700 \mathrm{nt}$ proBA mRNA, since it could not be detected with an 86 nt single-stranded DNA probe (probe 2) that covered only the region of the proBA mRNA leader region upstream of the intrinsic terminator sequence (Fig. 5b, c). Processing of mRNAs upstream of the intrinsic terminator present in the leader region has already been observed for the T-box-regulated thrS gene of B. subtilis, and contributes to the induced expression level in threonine-starved cells by stabilizing the downstream mRNA coding sequence (Condon et al., 1996; Even et al., 2005). We did not analyse the possible function of the processing step of the primary proBA transcript on mRNA stability.

\section{Induction of proBA transcription is sensitively controlled by proline starvation}

The Northern blot experiment documented in Fig. 5(c) shows that the expression of the proBA operon is induced when the $B$. subtilis cells are starved for proline. To investigate this in greater detail, we constructed a transcriptional fusion of the proBA regulatory region to a promoterless treA reporter gene (Schöck et al., 1996). We recombined the resulting proB-tre $A$ reporter gene fusion as a single copy into the $a m y E$ locus in the genome of $B$. subtilis strains that were either prototrophic [strain JSB5 $\left(\right.$ pro $^{+}$proB-treA)] or auxotrophic [strain JSB31 (proA proB-treA)] for proline (Table 1). When the prototrophic strain JSB5 was grown in SMM minimal medium in the absence of proline (Fig. 6a), expression of the proB-treA

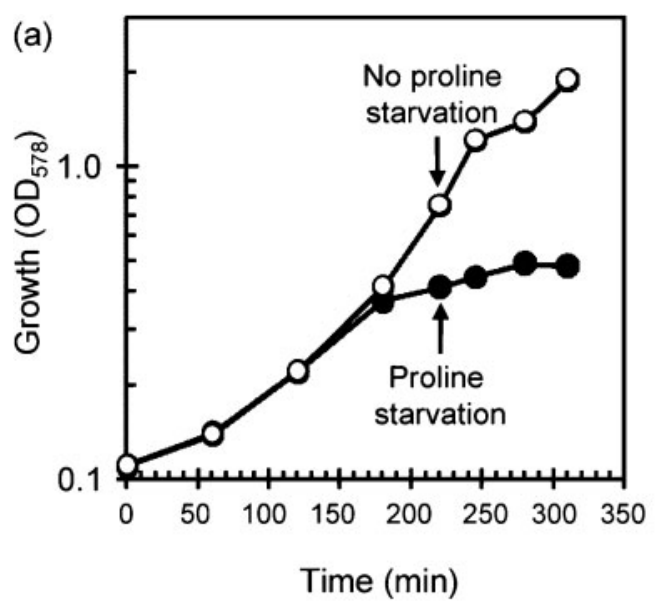

(b)

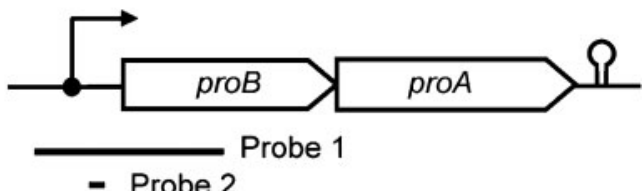

(c)

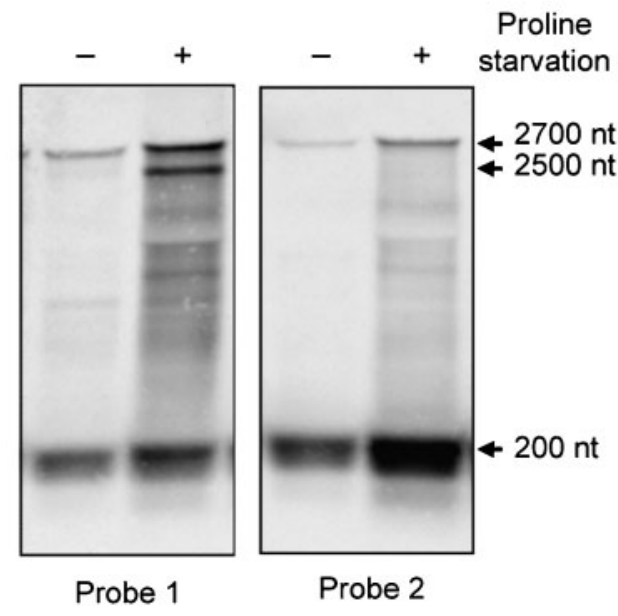

Fig. 5. Derepression of $p r o B$ transcription in response to proline starvation. (a) The proline-auxotrophic strain JSB41 (proG, proH, prol) was grown in SMM with either $10 \mathrm{mM}$ proline (no starvation for proline) or $0.6 \mathrm{mM}$ proline (starvation for proline). As soon as proline starvation set in for the proline-limited culture, cells were harvested from both cultures and total RNA was isolated. The RNA was separated according to size under denaturing conditions on a $1.4 \%$ agarose gel, and the proBA- and prol-specific transcripts were detected by hybridization with DIG-labelled single-stranded DNA probes (b) covering either the entire $5^{\prime}$ segment of the proBA transcript and part of the proB coding region (probe 1 ) or only part of the pro $B$ mRNA leader region (probe 2). The detected proBA mRNA leader, the full-length transcript and the processed mRNA species are displayed in (c).

reporter gene fusion remained at a low level during the entire growth cycle of the culture (Fig. 6b). This indicates that this $\mathrm{Pro}^{+}$B. subtilis strain did not experience any 

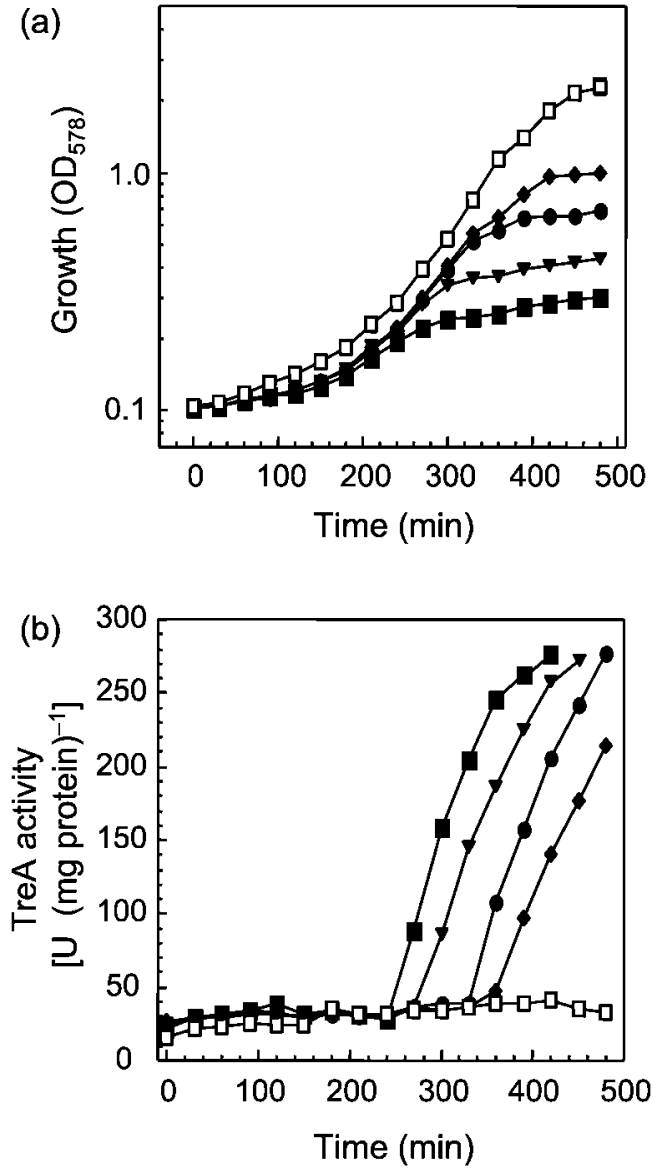

Fig. 6. Induction of pro $B-\operatorname{tre} A$ expression in response to proline starvation. The expression of a proB-tre $A$ reporter gene fusion was monitored in the proline prototrophic strain JSB5 (open symbols) and its proline-auxotrophic derivative strain JSB31 (filled symbols). Strain JSB5 was cultivated in SMM in the absence of proline ( $\square$ ) and strain JSB31 was propagated in SMM supplemented with $0.2 \mathrm{mM}(\boldsymbol{\nabla}), 0.4 \mathrm{mM}(\boldsymbol{\Delta}), 0.8 \mathrm{mM}(\bullet)$ or $1.2 \mathrm{mM}(\boldsymbol{\bullet})$ proline. Growth of the cultures was monitored (a), and by measuring the activity of the TreA reporter enzyme the expression of the proBtre $A$ transcriptional gene fusion present in strains JSB5 and JSB31 was assessed (b).

physiologically significant proline limitation during growth. In parallel, we grew the proline auxotrophic strain JSB31 in SMM containing $0.2,0.4,0.8$ or $1.2 \mathrm{mM}$ proline. Each of these concentrations of proline was limiting for cell growth and did not allow the cultures to reach the same cell densities as the wild-type strain (Fig. 6a). Strikingly, as soon as the growth of the proline-limited cultures of the Pro $^{-}$strain JSB31 started to slow down (Fig. 6a), transcription of the proB-treA reporter gene fusion was rapidly derepressed in each of these cultures, and proB-tre $A$ expression persisted at a strongly elevated level in the proline-starved B. subtilis cells (Fig. 6b). The amount of proline (more than $1.2 \mathrm{mM}$ ) required for the full growth of the Pro ${ }^{-}$mutant strain JSB31 is substantially higher than that needed to satisfy the auxotrophy of this JH642 (pheA1 $\operatorname{trpC2})$-derived strain for either L-tryptophan $(0.1 \mathrm{mM})$ or L-phenylalanine $(0.1 \mathrm{mM})$. We attribute this observation to the fact that $B$. subtilis can efficiently use proline as a sole carbon or nitrogen source (Fisher \& Debarbouille, 2002).

\section{Synthetic redesign of the proline specificity of the T-box control element in proBA}

The predicted secondary structure of the proBA mRNA leader sequence suggests that a CCU codon (Fig. 3a) functions as the specifier element and confers proline specificity upon the regulation of proBA via the T-box system. Studies with several T-box-regulated genes have revealed that the amino acid specificity of a given T-box system can be altered through mutational changes of the specifier codon (Grundy \& Henkin, 1993; Luo et al., 1997; Marta et al., 1996; Putzer et al., 1995). Hence, the redesign of the specificity of a given T-box system by manipulating the putative specifier codon is a genetic approach that can identify a particular codon in the $5^{\prime}$-leader region of the transcript as the specifier. To provide evidence that the $\mathrm{CCU}$ codon highlighted in Fig. 3(a) indeed confers proline specificity upon the proBA T-box element, we changed it via site-directed mutagenesis to UUC, a codon that interacts with an anti-codon of a Phe-tRNA. Consequently, the mutated proBA T-box element should cause derepression of proBA transcription in cells starved for phenylalanine and simultaneously eliminate their response to proline starvation. We inserted an appropriately modified proB-treA fusion (CCT changed to TTC) into a B. subtilis strain that is auxotrophic for both Pro and Phe (Table 1). In the proBtreA fusion strain (JSB31) carrying the wild-type CCU specifier codon, proline starvation induced the expression of the reporter gene fusion about 13-fold, but there was no derepression of proB-treA expression when the cells were starved for phenylalanine (Table 2). Conversely, the expression of the proB-treA fusion with the Phe-specific UUC codon instead of the natural CCU proline-specific specifier element no longer changed in response to proline starvation. Instead, transcription of the mutant proB-treA reporter fusion was induced about sevenfold in response to phenylalanine starvation (Table 2). This experiment thus provides solid evidence that the CCU codon highlighted in Fig. 3(a) is indeed the proline-specifier codon for the T-box control system of the proBA operon from B. subtilis.

\section{DISCUSSION}

Two interconnected proline biosynthetic routes are present in B. subtilis, which serve for the supply of proline either as a building block for protein biosynthesis or as an osmostress protectant (Fig. 1) (Belitsky et al., 2001). Since the biosynthesis of amino acids is energetically expensive (Akashi \& Gojobori, 2002), B. subtilis has to carefully adjust its proline biosynthetic capacities to produce the amounts needed for these very different physiological tasks (Bremer, 
Table 2. Synthetic redesign of the proline specificity of the proBA T-box element

\begin{tabular}{|c|c|c|c|c|c|c|c|}
\hline \multirow[t]{3}{*}{ Reporter strain* } & \multirow[t]{3}{*}{ Specifier codon } & \multicolumn{6}{|c|}{ TreA activity [U (mg protein $\left.)^{-1}\right]$} \\
\hline & & \multicolumn{2}{|c|}{ Starvation for proline } & \multirow[t]{2}{*}{ Fold-induction } & \multicolumn{2}{|c|}{$\begin{array}{l}\text { Starvation for } \\
\text { phenylalanine }\end{array}$} & \multirow[t]{2}{*}{ Fold-induction } \\
\hline & & - & + & & - & + & \\
\hline JSB31 & CGAA CCU GCCU & $21 \pm 4$ & $270 \pm 21$ & 12.9 & $12 \pm 2$ & $10 \pm 1$ & 0.8 \\
\hline
\end{tabular}

*These strains are phenylalanine (pheA1) and proline auxotrophs (proA $\times$ pEPV1T), and both strains carry the same $\Phi\left(\right.$ pro $B^{\prime}-$ treA) reporter gene fusion. The two strains differ in that strain JB31 carries the proline-specific CCT specifier codon, while its mutant derivative JSB31-mutl carries instead a phenylalanine-specific TTC specifier codon in the $\Phi\left(\right.$ pro $\left.B^{\prime}-t r e A\right)$ fusion construct. The strains were cultivated for the proline starvation experiment either in the presence of excess proline $(10 \mathrm{mM})$ or with limiting amounts of proline $(0.2 \mathrm{mM})$; these cultures contained $0.1 \mathrm{mM}$ phenylalanine to satisfy the auxotrophic needs of the strains. For the phenylalanine starvation experiment, the strains were cultivated either in the presence of excess phenyalanine $(0.1 \mathrm{mM})$ or with limiting amounts of phenylalanine $(0.016 \mathrm{mM})$; these cultures contained $10 \mathrm{mM}$ proline to satisfy the auxotrophic needs of the strains. Growth of the strains was monitored and the expression of the $\Phi\left(\right.$ pro $B^{\prime}-$ treA $)$ reporter gene fusion was measured after starvation for proline or phenylalanine had set in (after about $7 \mathrm{~h}$ ).

2002; Whatmore et al., 1990). Our data show that the transcription of the anabolic proBA operon and that of the proI gene is regulated through a proline-responsive $\mathrm{T}$-box regulatory system. This tRNA-responsive riboswitch (Green et al., 2010; Gutiérrez-Preciado et al., 2009; Henkin, 2008; Winkler, 2007) links the production of the anabolic ProBProA-ProI proline biosynthetic enzymes (Fig. 1) to the prevalent cellular proline pool so that no shortage of this amino acid as a building block for protein biosynthesis occurs (Fig. 6).

Comprehensive in silico surveys suggest that prolineresponsive $\mathrm{T}$-box systems are present in a large number of Gram-positive bacteria (Gutiérrez-Preciado et al., 2009; Vitreschak et al., 2008; Wels et al., 2008). Genetic control of the transcription of the proBA and proI genes via a T-box system has been predicted by the in silico mining of the $B$. subtilis genome sequence for the presence of T-box signature sequences (Chopin et al., 1998; Gutiérrez-Preciado et al., 2009; Vitreschak et al., 2008; Wels et al., 2008; Winkler, 2007). Our data show that the predicted T-box systems for the anabolic proBA and proI genes are indeed functional. Furthermore, they represent the first experimental proof, to our knowledge, of the functioning of a proline-responsive $\mathrm{T}$ box regulatory system in any microbial species.

Northern blot analysis of the proBA transcripts in cells that are not starved of proline revealed the constitutive synthesis of the mRNA leader region and a limited amount of the fulllength transcript (Fig. 5c). In agreement with the transcription pattern generally established for T-box-regulated genes (Green et al., 2010; Gutiérrez-Preciado et al., 2009), proline starvation did not appreciably reduce the amount of the proBA leader transcript but boosted the synthesis of the fulllength proBA mRNA (Fig. 5c). In addition, in prolinestarved cells, a proBA mRNA species was produced that lacked about $200 \mathrm{nt}$ at its $5^{\prime}$ end. We have not studied how this processed proBA transcript is generated and what the physiological consequences of its production might be with respect to the cellular levels of the ProB and ProA proteins. However, there is a precedent for such a processing event in the context of a T-box regulatory system. The thrS gene encodes a threonyl-tRNA synthetase, and its transcript is processed at a site just upstream of the intrinsic transcription terminator in the leader mRNA sequence. This processing event increases the stability of the downstream mRNA segment and thereby enhances production of the threonyl-tRNA synthetase in threonine-starved cells (Condon et al., 1996). Given what has been reported in the context of the thrS T-box system, we are tempted to speculate that the processing of the primary proBA transcript prolongs the lifespan of the cleaved mRNA and thereby boosts ProB and ProA synthesis in B. subtilis cells starved for proline. A preliminary investigation of the proI transcript in proline-starved $B$. subtilis cells by Northern blot analysis did not reveal any evidence for a processing event of the fulllength proI mRNA (J. Brill and E. Bremer, unpublished results).

The specificity of a given T-box system is conferred by a specifier codon strategically positioned in a bulged region of the first predicted stem structure of the mRNA leader region (the specifier domain), and by the interaction of this codon with the anti-codon of the uncharged cognate tRNA. As expected from the function of the B. subtilis proBA- and proI-encoded proteins in proline synthesis, the specifier codon in both loci is a proline-specific codon, CCU (Fig. 3a, b). Proline is encoded by four codons (CCA, CCG, CCU and CCC), and the CCU codon employed as the specifier in proBA and proI (Fig. 3) is one of the two proline-specific codons (CCG and CCU) that are preferentially used in protein-encoding genes of B. subtilis (Kanaya et al., 1999). It should be noted in this context that $B$. subtilis possesses only one tRNA ${ }^{\text {Pro }}$ (anticodon: 5-methoxyUGG) and that this single tRNA recognizes all four proline-encoding codons (Yamada et al., 2005). 
Previous studies have shown that the amino acid specificity of a given T-box system can be synthetically redesigned by mutational changes in the specifier codon (Grundy \& Henkin, 1993; Grundy et al., 1997; Luo et al., 1997; Marta et al., 1996; Putzer et al., 1995). Following these leads, we altered the CCU proline-specifier codon in the proBA mRNA leader sequence to a phenylalanine-specific UUC codon, and this change supplanted the original prolinespecific response with a phenylalanine-specific regulatory response (Table 2). The degree of derepression of proBA transcription of the mutant T-box system in response to phenylalanine starvation (sevenfold) is similar to that of the original T-box system in response to proline starvation (13-fold) (Table 2). This experiment also illustrates the fact that simply starving B. subtilis cells for an amino acid other than proline does not trigger an indiscriminate derepression of the expression of the proBA and proI genes.

In addition to the proline-responsive transcriptional control of the proBA and proI genes through a T-box regulatory mechanism, the enzyme activity of the $B$. subtilis ProB protein is subject to feedback control by very low concentrations of proline (Fig. 1); $7.5 \times 10^{-6} \mathrm{M}$ proline is sufficient to inhibit $50 \%$ of the activity of the purified ProB enzyme (Chen et al., 2007). Hence, combined transcriptional and post-transcriptional regulatory mechanisms allow the $B$. subtilis cell to sensitively control its proline pool produced via the anabolic ProB-ProA-ProI route. As a consequence, a wasteful overproduction of proline is prevented when it is made as a precursor for protein synthesis. It is immediately apparent that the above-discussed control mechanisms make the anabolic ProB-ProA-ProI proline biosynthetic route unsuitable for providing the B. subtilis cell with the very large amounts of proline it needs for osmostress protection (Bremer, 2002; Whatmore et al., 1990).

\section{ACKNOWLEDGEMENTS}

We thank B. Belitsky (Tufts University, USA), J. Hoch (The Scripps Research Institute, USA), M. Itaya (Keio University, Japan), T. Tanaka (Tokai University, Japan), M. Jebbar (Marburg University, Germany) and B. Kempf (Marburg University, Germany) for kindly providing bacterial strains and plasmids. We appreciate the help of Vickie Koogle in the editing of the manuscript. This study was financially supported by grants from the Bundesministerium für Bildung und Forschung (BMBF) via the Bacell-SysMo2 consortium (to E. B.), the LandesOffensive zur Entwicklung wissenschaftlich-ökonomischer Exzellenz (LOEWE) program of the State of Hessen (via the Centre for Synthetic Microbiology; SynMicro, Marburg) (to E. B), the Fonds der Chemischen Industrie (to E.B) and the Centre National de la Recherche Scientifique (CNRS) (UPR 9073) - Université Paris VIIDenis Diderot (to H. P.). J. B. gratefully acknowledges the receipt of a short-term fellowship from the Boehringer Ingelheim Fonds to support her work in the laboratory of H. P. in Paris.

\section{REFERENCES}

Akashi, H. \& Gojobori, T. (2002). Metabolic efficiency and amino acid composition in the proteomes of Escherichia coli and Bacillus subtilis. Proc Natl Acad Sci U S A 99, 3695-3700.
Belitsky, B. R., Brill, J., Bremer, E. \& Sonenshein, A. L. (2001). Multiple genes for the last step of proline biosynthesis in Bacillus subtilis. J Bacteriol 183, 4389-4392.

Bremer, E. (2002). Adaptation to changing osmolarity. In Bacillus subtilis and its Closest Relatives, pp. 385-391. Edited by A. L. Sonenshein, J. A. Hoch \& R. Losick. Washington, DC: American Society for Microbiology.

Chen, M., Cao, J., Zheng, C. \& Liu, Q. (2006). Directed evolution of an artificial bifunctional enzyme, $\gamma$-glutamyl kinase $/ \gamma$-glutamyl phosphate reductase, for improved osmotic tolerance of Escherichia coli transformants. FEMS Microbiol Lett 263, 41-47.

Chen, M., Wei, H., Cao, J., Liu, R., Wang, Y. \& Zheng, C. (2007). Expression of Bacillus subtilis proBA genes and reduction of feedback inhibition of proline synthesis increases proline production and confers osmotolerance in transgenic Arabidopsis. J Biochem Mol Biol 40, 396-403.

Chopin, A., Biaudet, V. \& Ehrlich, S. D. (1998). Analysis of the Bacillus subtilis genome sequence reveals nine new T-box leaders. Mol Microbiol 29, 662-664.

Condon, C., Putzer, H. \& Grunberg-Manago, M. (1996). Processing of the leader mRNA plays a major role in the induction of thrS expression following threonine starvation in Bacillus subtilis. Proc Natl Acad Sci U S A 93, 6992-6997.

Csonka, L. N. \& Leisinger, T. (2007). Chapter 34.6.1.4, Biosynthesis of proline. In EcoSal-Escherichia coli and Salmonella: Cellular and Molecular Biology. Edited by A. Böck, R., III, J. B. Kaper, P. D. Karp, F. C. Neidhardt, T. Nystrom, J. M. Slauch, C. L. Squires \& D. Ussery. Washington, DC: American Society for Microbiology.

Even, S., Pellegrini, O., Zig, L., Labas, V., Vinh, J., BréchemmierBaey, D. \& Putzer, H. (2005). Ribonucleases J1 and J2: two novel endoribonucleases in B. subtilis with functional homology to E. coli RNase E. Nucleic Acids Res 33, 2141-2152.

Fisher, S. H. \& Debarbouille, M. (2002). Nitrogen source utilization and its regulation. In Bacillus subtilis and its Closest Relatives, pp. 181231. Edited by A. L. Sonenshein, J. A. Hoch \& R. Losick. Washington, DC: American Society for Microbiology.

Foy, N., Jester, B., Conant, G. C. \& Devine, K. M. (2010). The T box regulatory element controlling expression of the class I lysyl-tRNA synthetase of Bacillus cereus strain 14579 is functional and can be partially induced by reduced charging of asparaginyl-tRNAAsn. BMC Microbiol 10, 196

Gotsche, S. \& Dahl, M. K. (1995). Purification and characterization of the phospho- $\alpha(1,1)$ glucosidase (TreA) of Bacillus subtilis 168 . J Bacteriol 177, 2721-2726.

Green, N. J., Grundy, F. J. \& Henkin, T. M. (2010). The T box mechanism: tRNA as a regulatory molecule. FEBS Lett 584, 318-324.

Grundy, F. J. \& Henkin, T. M. (1993). tRNA as a positive regulator of transcription antitermination in B. subtilis. Cell 74, 475-482.

Grundy, F. J., Hodil, S. E., Rollins, S. M. \& Henkin, T. M. (1997). Specificity of tRNA-mRNA interactions in Bacillus subtilis tyrS antitermination. J Bacteriol 179, 2587-2594.

Grundy, F. J., Yousef, M. R. \& Henkin, T. M. (2005). Monitoring uncharged tRNA during transcription of the Bacillus subtilis glyQS gene. J Mol Biol 346, 73-81.

Gutiérrez-Preciado, A., Henkin, T. M., Grundy, F. J., Yanofsky, C. \& Merino, E. (2009). Biochemical features and functional implications of the RNA-based T-box regulatory mechanism. Microbiol Mol Biol Rev 73, 36-61.

Hahne, H., Mäder, U., Otto, A., Bonn, F., Steil, L., Bremer, E., Hecker, M. \& Becher, D. (2010). A comprehensive proteomics and transcriptomics analysis of Bacillus subtilis salt stress adaptation. J Bacteriol 192, 870882. 
Harwood, C. R. \& Archibald, A. R. (1990). Growth, maintenance and general techniques. In Molecular Biological Methods for Bacillus, pp. 126. Edited by C. R. Harwood \& S. M. Cutting. Chichester, UK: John Wiley \& Sons.

Helmann, J. D. (1995). Compilation and analysis of Bacillus subtilis $\sigma^{\mathrm{A}}$-dependent promoter sequences: evidence for extended contact between RNA polymerase and upstream promoter DNA. Nucleic Acids Res 23, 2351-2360.

Henkin, T. M. (2008). Riboswitch RNAs: using RNA to sense cellular metabolism. Genes Dev 22, 3383-3390.

Holtmann, G. \& Bremer, E. (2004). Thermoprotection of Bacillus subtilis by exogenously provided glycine betaine and structurally related compatible solutes: involvement of $\mathrm{Opu}$ transporters. J Bacteriol 186, 1683-1693.

Itaya, M. (1992). Construction of a novel tetracycline resistance gene cassette useful as a marker on the Bacillus subtilis chromosome. Biosci Biotechnol Biochem 56, 685-686.

Kanaya, S., Yamada, Y., Kudo, Y. \& Ikemura, T. (1999). Studies of codon usage and tRNA genes of 18 unicellular organisms and quantification of Bacillus subtilis tRNAs: gene expression level and species-specific diversity of codon usage based on multivariate analysis. Gene 238, 143-155.

Kappes, R. M., Kempf, B., Kneip, S., Boch, J., Gade, J., MeierWagner, J. \& Bremer, E. (1999). Two evolutionarily closely related $\mathrm{ABC}$ transporters mediate the uptake of choline for synthesis of the osmoprotectant glycine betaine in Bacillus subtilis. Mol Microbiol 32, 203-216.

Kempf, B. \& Bremer, E. (1998). Uptake and synthesis of compatible solutes as microbial stress responses to high-osmolality environments. Arch Microbiol 170, 319-330.

Luo, D., Leautey, J., Grunberg-Manago, M. \& Putzer, H. (1997). Structure and regulation of expression of the Bacillus subtilis valyltRNA synthetase gene. J Bacteriol 179, 2472-2478.

Marta, P. T., Ladner, R. D. \& Grandoni, J. A. (1996). A CUC triplet confers leucine-dependent regulation of the Bacillus subtilis ilv-leu operon. J Bacteriol 178, 2150-2153.

Miller, J. H. (1992). A Short Course in Bacterial Genetics. A Laboratory Manual and Handbook for Escherichia coli and Related Bacteria. Cold Spring Harbor, NY: Cold Spring Harbor Laboratory.

Ogura, M., Kawata-Mukai, M., Itaya, M., Takio, K. \& Tanaka, T. (1994). Multiple copies of the proB gene enhance degS-dependent extracellular protease production in Bacillus subtilis. J Bacteriol 176, 5673-5680.

Ordal, G. W. \& Gibson, K. J. (1977). Chemotaxis toward amino acids by Bacillus subtilis. J Bacteriol 129, 151-155.

Putzer, H., Laalami, S., Brakhage, A. A., Condon, C. \& GrunbergManago, M. (1995). Aminoacyl-tRNA synthetase gene regulation in
Bacillus subtilis: induction, repression and growth-rate regulation. Mol Microbiol 16, 709-718.

Putzer, H., Condon, C., Brechemier-Baey, D., Brito, R. \& GrunbergManago, M. (2002). Transfer RNA-mediated antitermination in vitro. Nucleic Acids Res 30, 3026-3033.

Sambrook, J., Fritsch, E. F. \& Maniatis, T. E. (1989). Molecular Cloning: a Laboratory Manual, 2nd edn. Cold Spring Harbor, NY: Cold Spring Harbor Laboratory.

Schöck, F., Gotsche, S. \& Dahl, M. K. (1996). Vectors using the phospho- $\alpha$-(1,1)-glucosidase-encoding gene treA of Bacillus subtilis as a reporter. Gene 170, 77-80.

Spiegelhalter, F. \& Bremer, E. (1998). Osmoregulation of the $o p u E$ proline transport gene from Bacillus subtilis: contributions of the sigma A- and sigma B-dependent stress-responsive promoters. Mol Microbiol 29, 285-296.

Steil, L., Hoffmann, T., Budde, I., Völker, U. \& Bremer, E. (2003). Genome-wide transcriptional profiling analysis of adaptation of Bacillus subtilis to high salinity. J Bacteriol 185, 6358-6370.

Vitreschak, A. G., Mironov, A. A., Lyubetsky, V. A. \& Gelfand, M. S. (2008). Comparative genomic analysis of T-box regulatory systems in bacteria. RNA 14, 717-735.

von Blohn, C., Kempf, B., Kappes, R. M. \& Bremer, E. (1997). Osmostress response in Bacillus subtilis: characterization of a proline uptake system (OpuE) regulated by high osmolarity and the alternative transcription factor sigma B. Mol Microbiol 25, 175-187.

Wels, M., Groot Kormelink, T., Kleerebezem, M., Siezen, R. J. \& Francke, C. (2008). An in silico analysis of T-box regulated genes and T-box evolution in prokaryotes, with emphasis on prediction of substrate specificity of transporters. BMC Genomics 9, 330.

Whatmore, A. M., Chudek, J. A. \& Reed, R. H. (1990). The effects of osmotic upshock on the intracellular solute pools of Bacillus subtilis. J Gen Microbiol 136, 2527-2535.

Winkler, W. C. (2007). RNA-mediated regulation in Bacillus subtilis. In Bacillus: Cellular and Molecular Biology, pp. 167-214. Edited by P. Graumann. Norfolk, UK: Caister Academic Press.

Yamada, Y., Matsugi, J., Ishikura, H. \& Murao, K. (2005). Bacillus subtilis tRNA ${ }^{\text {Pro }}$ with the anticodon mo $^{5} \mathrm{UGG}$ can recognize the codon CCC. Biochim Biophys Acta 1728, 143-149.

Yousef, M. R., Grundy, F. J. \& Henkin, T. M. (2005). Structural transitions induced by the interaction between tRNA ${ }^{\text {Gly }}$ and the Bacillus subtilis glyQS T box leader RNA. J Mol Biol 349, 273-287.

Zuker, M. (2003). Mfold web server for nucleic acid folding and hybridization prediction. Nucleic Acids Res 31, 3406-3415.

Edited by: T. Abee 